\title{
RESENHA DO LIVRO “TEACHER PREPARATION IN SCOTLAND” (FORMAÇÃO DE PROFESSORES NA ESCÓCIA)
}

\author{
BOOK REVIEW “TEACHER PREPARATION IN SCOTLAND
}

\section{REVISIÓN DEL LIBRO "PREPARACIÓN DE PROFESORES EN ESCOCIA"}

\author{
Amanda Oliveira Rabelo \\ Universidade Federal Fluminense - Brasil
}

\begin{abstract}
Resumo: Esta resenha objetiva destacar as ideias principais do livro "Teacher Preparation in Scotland" organizado por Rachel Shanks da Escócia. Efetuamos inicialmente o levantamento das ideias principais do livro, com destaque para a história e atualidade da formação de professores na Escócia, com suas fases, debates e forma de funcionamento, em especial o estágio supervisionado e a indução profissional; o principal lugar de formação docente, na universidade ou na escola; a discussão sobre a maior ênfase no conhecimento acadêmico ou prático; as parcerias entre as instituições; o impacto das políticas educacionais na formação de professores; a introdução de rotas alternativas e a educação online e a distância para suprir a carência de professores na Escócia; as formas de formação de professores, entre outras. Depois realizamos resumo dos seus capítulos, que contém temáticas variadas sobre a formação de professores na Escócia. Por fim, realizamos uma crítica de como o livro traz reflexões que são importantes para pensarmos a realidade e o futuro da formação de professores no Brasil.
\end{abstract}

Palavras chave: Formação de professores na Escócia; história e atualidade; indução profissional docente.

\begin{abstract}
This review aims to highlight the main ideas of the book "Teacher Preparation in Scotland" organized by Rachel Shanks from Scotland. We initially surveyed the main ideas of the book, with emphasis on the history and currentness of teacher training in Scotland, with its phases, debates and way of functioning, especially the supervised internship and professional induction; the main place of teacher training, at the university or at school; the discussion about the greater emphasis on academic or practical knowledge; partnerships between institutions; the impact of educational policies on teacher education; the introduction of alternative routes and online and distance education to fill the shortage of teachers in Scotland; forms of teacher education, among others. Then we summarize its chapters, which contain various topics on teacher education in Scotland. Finally, we made a critique of how the book brings reflections that are important to think about the reality and the future of teacher education in Brazil.
\end{abstract}

Keywords: Teacher training in Scotland; history and current events; teaching professional induction

Resumen: Esta revisión tiene como objetivo resaltar las ideas principales del libro "La preparación del profesorado en Escocia" organizado por Rachel Shanks de Escocia. Inicialmente realizamos un relevamiento de las ideas principales del libro, con énfasis en la historia y estado actual de la formación 
del profesorado en Escocia, con sus fases, debates y forma de funcionamiento, especialmente la pasantía supervisada y la inducción profesional; el lugar principal de formación del profesorado, en la universidad o en la escuela; la discusión sobre el mayor énfasis en el conocimiento académico o práctico; asociaciones entre instituciones; el impacto de las políticas educativas en la formación del profesorado; la introducción de rutas alternativas y educación en línea y a distancia para suplir la escasez de profesores en Escocia; formas de formación docente, entre otras. A continuación, resumimos sus capítulos, que contienen diversos temas sobre la formación del profesorado en Escocia. Finalmente, hicimos una crítica de cómo el libro trae reflexiones que son importantes para que pensemos sobre la realidad y el futuro de la formación docente en Brasil.

Palabras clave: Formación docente na Escocia; historia y actualidad; enseñanza de la inducción profesional.

\section{Introdução}

Este livro organizado pela professora Rachel Shanks da Universidade de Aberdeen na Escócia, somado com a contribuição dos principais pesquisadores do país da área, trazendo resultados de um grupo de 11 membros da "Measuring Quality in Initial Teacher Education" (MQuITE) que pesquisam sobre formação docente na Escócia e envolvendo as Universidades que oferecem formação de professores na Escócia. Aprofunda tanto a história (desde o século XIX) como a atualidade da "Formação de professores na Escócia", desde a formação inicial docente até a indução profissional dos professores na sua carreira, desde a formação presencial à formação a distância, desde a formação católica à episcopal.

Como parte de uma série de livros editados pela Emerald Publishing sobre a formação de professores de países, nos seus 14 capítulos este livro aborda de forma abrangente como se dá a formação docente na Escócia, com os seus debates e questões particulares.

São incluídas questões sobre:

a) a história e atualidade da formação de professores na Escócia, com suas fases, debates e forma de funcionamento, em especial o estágio supervisionado e a indução profissional;

b) o principal lugar de formação docente, na universidade ou na escola, e a consequente discussão sobre a maior ênfase no conhecimento acadêmico ou prático, o que também leva a discussão da necessidade de parcerias entre as instituições;

c) o impacto das políticas educacionais na formação de professores, como, por exemplo: a mudança de currículo das escolas de 3 a 18 anos em 2010, que passou a demandar dos professores que ensinem os jovens e cuidem do seu bem-estar;

d) a introdução da educação online e a distância para suprir a carência de professores no país; 
e) há capítulos sobre as formas de formação de professores, contendo recomendações para a formação e indução de professores, incluindo área negligenciadas.

A formação de professores na Escócia é exclusivamente efetuada em Universidades em nível superior, o que inclui 4 anos de bacharelado, 1 ano de um programa de pós-graduação chamado "Professional Graduate Diploma in Education - PGDE", formação de professores online e à distância ou novas rotas de formação de professores. Depois disso há a obrigatoriedade de um período de indução profissional docente no ensino que lhe dá depois o registro completo de professor pelo "General Teaching Council for Scotland”(GTCS).

\section{Descrição dos capítulos do livro}

O primeiro capítulo, de Moira Hulme, aborda a história da formação de professores na Escócia de 1872 a 1920, discutindo o lugar da Universidade na formação de professores e o lugar do conhecimento e da prática, também, mais recentemente, sobre como formar melhor alguém para ser professor. O segundo capítulo, da mesma autora, continua a efetuar um histórico da formação de professores na Escócia de 1920 a 2000, abrangendo o movimento de passar de uma formação "monotécnica" (com uma disciplina única) do centro de treinamento para a incorporação ao setor universitário, bem como a contínua discussão sobre o lugar do conhecimento e habilidade na docência.

O currículo da Escócia (Curriculum for Excellence - CfE) é destaque da discussão efetuada por Carrie McLennan no capítulo 3 sobre a formação de professores "PostDevolution" (pós-devolução) de 1999-2007, discutindo a discussão, revisão e produção do CfE e das consequentes alterações que as instituições de formação de professores (inclusive em "Colleges" que são faculdades que só têm graduação, que tinham um enfoque mais prático de formação) que culminaram em que a partir de 2001 toda a formação docente acontecesse somente em Universidades.

No capítulo 4, Anna Beck e Paul Adams discutem as parcerias e a formação de professores, descrevendo o relatório Donaldson (2011) “Teaching Scotland's Future” (Futuro do ensino na Escócia) realizado no contexto pós-recessão de 2008, de austeridade e da campanha da independência da Escócia e do Brexit. Um das grandes questões abordadas é a necessidade de uma revisão da formação de professores com o fortalecimento de parcerias entre universidades, autoridades locais e escolas, bem como a modernização e "revigoramento" do profissionalismo docente.

Já o capítulo 5, de autoria de Sandra Eady, explora o impacto dos discursos, políticas e práticas nos cursos de bacharelado em Educação (que acontece em 4 anos de estudo). Critica- 
se o desenvolvimento desses graus e o envolvimento e influência de diferentes partes interessadas, como as instituições de Ensino Superior, o GTCS com a acreditação profissional e também as escolas e autoridades locais no que tange à prática profissional. A autora demarca que os bacharelados em educação são construídos de diversas forma, existindo as rotas flexíveis e os questionamentos sobre a sua qualidade. Assim, duas questões se destacam: a necessidade de relação entre o estudo acadêmico com a experiência prática de sala de aula (relação teoria e prática); as parcerias em relação aos graus de bacharelado.

No capítulo 6, Ellis descreve como o PGDE (Professional Graduate Diploma in Education) é organizado, sendo um curso de pós-graduação de 1 ano para graduados na Escócia se formarem como professores, originando de um debate e uma transição acontecida em 1991, mas denominada dessa forma no ano de 2005/2006. O curso tem 18 semanas de estudo a tempo integral na Universidade e 18 semanas a tempo integral na escola, considerando que a chave é a integração entre teoria e prática. A autora descreve que há critérios de seleção e recrutamento mínimos para que um estudante possa fazer um PGDE e fornece uma análise de duas pesquisas sobre quem escolhe essa forma de preparação de professores, destacando reflexões sobre os critérios, questões de gênero (como o incentivo para homens serem professores primários), étnicas (a garantia que os professores das mais variadas etnias não serem discriminados), as dificuldades de recrutamento de professores, em especial em área rurais, dentre outras questões.

No capítulo 7, David Johnston enfoca o que é denominado na Escócia como colocação escolar (school placement ) que é um elemento obrigatório da preparação de professores na Escócia, equivalente ao estágio supervisionado ou prática pedagógica do Brasil. Destaca-se o estágio como o cerne da discussão entre "a virada para a universidade" e a "virada prática que está presente na atual questionamento do papel da universidade na formação de professores e na defesa da preparação de professores na escola, como o programa "Teach First". Enfim, existem no mundo várias denominações e modelos de formação de professor (mais práticos; mais reflexivos; mais focados na justiça social, igualdade e inclusão; etc). Contudo, há um consenso de que a oportunidade de aprender com a prática na escola é um elemento essencial na formação inicial de professores, sendo um importante ritual de passagem.

Na Escócia a “colocação escolar" mínima é de 30 semanas na graduação e 18 semanas no PGDE, onde a Universidade informa o número de alunos que farão estágio e o GTCS insere os alunos em um sistema que os aloca em locais próximos. O autor descreve pesquisas que mostram que nem todos os futuros professores têm experiências boas de estágio, sendo por vezes pouco orientados, ou apoiados pela Universidade e pela escola. Descreve-se algumas pesquisas sobre o que influencia um bom estágio e analisa-se entrevistas de alunos sobre o 
estágio. Para o autor existe uma natureza relacional do estágio, os alunos-professores contribuem significativamente para o tipo de apoio que recebem durante o estágio, por isso é preciso evitar falar sobre estágio "bom" ou "mal", sendo preciso levar em consideração a interdependência relacional entre os agentes individuais e sociais.

Sobre a origem e a atualidade da preparação de professores on-line e à distância, o capítulo 8 de autoria de Morag Redford, explica que as novas rotas, introduzidas na Escócia de 2014 a 2018, são o resultado de um esforço para suprir a escassez persistente de professores em matérias específicas e, particularmente, em áreas rurais. Cabe destacar que na Escócia 83\% das pessoas vivem em 2\% da área territorial do país. Iniciando em 1994 e aumentando até 2018, tais programas formaram quase 600 professores primários e mais de 50 professores secundários de 2014 a 2018. A autora diz que não é possível saber se os programas terminarão, pois depende da necessidade de professores em especial nas áreas rurais.

No capítulo 9, "Formação inicial de professores em nível de mestrado", Aileen Kennedy e Nicola Carse investigam os movimentos no sentido de tornar o ensino uma profissão docente em nível de mestrado, tanto globalmente quanto na Escócia. Os argumentos de que o ensino seja uma profissão de nível de mestrado giram em torno de melhorar a qualidade do professor, aumentar a capacidade dos professores de pensar criticamente, criar professores mais engajados e focados na pesquisa e para atrair pessoas para a profissão. Existindo três tipos diferentes de oferta de mestrado (mais ou menos completos, mais ou menos críticos e/ou técnicos), procurados para progressão na carreira, dar aulas em disciplinas específicas, entre outros. As autoras defendem que é preciso raciocinar por que isso está acontecendo e se é a coisa certa a fazer, pois pode ser que esta estratégia de formar os professores em nível de mestrado seja só para manter uma competitividade internacional (em uma competição global neoliberal), sem um suporte da ideia que aumentar o nível de formação de professores signifique realmente ter professores melhores, mais críticos, engajados.

A organizadora do livro, Rachel Shanks, explica e analisa, no capítulo 10, o elemento final para se tornar um professor registrado na Escócia: o processo de indução. A autora analisa a situação dos novos professores que desde o século XIX tinham que passar por um estágio probatório. Em 2002 foi introduzido o Esquema de Indução de Professores na Escócia, que realizaria a transição do "professor estudante" ao professor totalmente registrado, onde os professores teriam 1 ano de contrato (ou uma rota alternativa mais longa para quem não pode fazer a indução em tempo integral) com o apoio de um professor mentor, tempo reduzido de horas de sala de aula (4 dias na semana em sala de aula e 1 para desenvolvimento profissional), tempo para seu desenvolvimento profissional para suprir as várias pressões da indução em uma 
nova profissão. A autora mostra dados que este programa na Escócia tem alocado cerca de 2 a 3 mil professores estudantes por ano, mas destaca questões como a alocação de professores ser aleatória (gerando níveis diferentes de satisfações e suportes), o suporte e a aprendizagem profissional. Examina-se três tensões específicas dentro do Esquema de Indução de Professores na Escócia: 1) as responsabilidades duplas dos mentores de apoio e avaliação; 2) a posição vulnerável dos professores do ano de indução (com falta de poder); 3) o papel das universidades na indução de professores (que não estão envolvidas no esquema de indução da Escócia, mas podem estar com a necessidade da formação de professores a nível de mestrado). Conclui-se com possíveis desenvolvimentos futuros, como a formação de redes para professores em escolas menores.

O capítulo 11 retorna às origens da preparação de professores na Escócia, traçando especificamente a história da preparação de professores católicos. Stephen McKinney explora essa história decorrente do crescimento da comunidade católica na Escócia no século XIX.

Já no capítulo 12, "História concisa do Colégio Episcopal de Formação de Professores", Stephen McKinney e Roger Edwards fornecem uma contribuição em uma área pouco pesquisada da história da formação de professores escoceses: a evolução da Igreja Episcopal. Delineando os diferentes modelos de escola episcopal, os autores examinam, por fim, o fechamento do Episcopal Training College (de formação de professores) em 1934 e a diminuição do número de escolas episcopais no século XX.

O penúltimo capítulo, capítulo 13, de Mark Carver, fornece um relato de como o campo de educação de professores de língua inglesa entrou e saiu da universidade na Escócia, assim como discute questões sobre educação e linguística.

O livro conclui com o capítulo "O futuro da formação de professores Caledoniana" de Robert Doherty que efetua reflexões críticas e sugestões de possíveis futuros com base na compreensão do contexto histórico e prática atual de preparação de professores na Escócia/Caledônia. Três futuros possíveis são explorados com base nos aspectos políticos, econômicos, socioculturais:

1) O futuro em perspectiva, ou seja, mais do mesmo, onde a formação de professores é levada a uma continuidade, mantendo um espaço permanente na preocupação do governo, mas de forma tecnocrática, regulatória. Com os professores universitários sendo mais importantes na formação docente, mas negligenciados pelos professores das escolas.

2) O futuro "Blade Runner", uma visão abertamente pessimista, com declínio econômico, desemprego, movimentos políticos extremistas e pela desigualdade, desrespeito

\footnotetext{
${ }^{1}$ Que é um termo que remete à origem romana da Escócia.
} 
pela classe trabalhadora, com políticas de austeridade, com aumento do individualismo e competição entre professores, em uma formação tecnicista, o modelo de formação universitário entra em declínio;

3) O "Futuro Iluminado pelo Sol”, uma visão extremamente otimista, onde a Escócia torna-se mais autônoma nas suas decisões políticas, sustentável, um lugar desejável de viver, com redução de pobreza e mudanças nas oportunidades de trabalho, onde o professor é uma das profissões mais desejáveis, requerendo nível de mestrado, com um período de indução de 1 a 3 anos, incluindo no seu trabalho um tempo parcial para estudo, inovadores, com um crescente número de professores fazendo doutorado.

O autor conclui destacando a importância da formação de professores e como sua qualidade pode ser usada como um indicador para a saúde de um sistema educacional, também destacando a importância da formação de professores construída tanto academicamente como no campo da prática, a partir das parcerias.

\section{Correlações e reflexões sobre o livro para a formação de professores no Brasil}

Apresentados os capítulos espero ter provocado várias questões, curiosidades e associações em quem lê esta resenha, como eu fiquei ao ler este livro, associando com a realidade da formação de professores no Brasil. Citarei 8 considerações que esta leitura mais me interpelou:

1- Em primeiro lugar, podemos analisar correlações entre a história e atualidade da formação de professores na Escócia e no Brasil, como as questões de gênero e religião na formação de professores, mas em especial a tendência mais recente à Universitarização da formação de professores, com uma disputa entre tipos de instituições e a discussão sobre a maior importância da teoria ou da prática nessa formação; percebemos, então, que esta não é uma questão superada, mas que ainda precisamos refletir muito sobre uma verdadeira união entre teoria e prática.

2- Outra questão que está sendo muito discutida no Brasil e que percebemos que na Escócia eles estão um poucos adiantados nesta efetivação é com relação às parcerias das instituições com a escola e com os órgão governamentais, portanto acredito que possamos aprender um pouco com a experiência da Escócia e refletir mais sobre a efetivação destas parcerias e cooperações no Brasil, de acordo com a nossa realidade, refletindo sobre os contextos, escolas e governos locais e nacionais.

3- Uma questão que me preocupou muito foi a percepção de que as rotas alternativas de formação de professores tem sido cada vez mais utilizadas e defendidas, o que não acontece 
só na Escócia, como exemplo, surge o PGDE (que ainda prima por alguma qualidade e crítica, em especial por ser uma pós-graduação), o ensino a distância (que também pode primar pela qualidade e crítica, mas será que consegue formar bem um professor?), o programa "Teach First", "Teach for America" e o "Ensina" no Brasil (ver também ZEICHNER, 2013; 2014), sendo preciso refletir para nos desatar das amarras das influências globais nas políticas de educação de professores, com a inserção de "rotas alternativas" que visam a destruição ou substituição do sistema universitário de educação pela competição da economia de mercado. No entanto, este debate está atrelado às políticas e à profissionalização/valorização dos professores, pois se ninguém quer ser mais professor, se existe carência de professores ou grande abandono docente (o que percebemos com o livro que também acontece na Escócia), as rotas alternativas podem ganhar cada vez mais espaço para suprir rapidamente esta carência e se tornar uma área mais atraente para quem deseja uma rápida e fácil formação.

4- Refletimos também sobre a colocação escolar na Escócia comparando com o estágio na formação de professores no Brasil, encontrando discussões comuns entre o questionamento do papel da universidade e da escola nesta fase, bem como o consenso da sua importância. Entretanto, percebemos o quanto a sua duração na Escócia é maior do que no Brasil, mas existindo também alunos que não têm boas experiências no estágio, assim precisamos refletir sobre a importância de ampliar a carga horária no Brasil (em especial com bolsas), também de se efetuar redes de parcerias para que estes alunos sejam recebidos nas escolas por professores que tenham interesse e qualidade para receber tais alunos, e analisar a questão da natureza relacional do estágio que destaca Johnston no seu capítulo.

5- Consideramos que é preciso pensar sobre a necessidade de cursos de formação a distância, mas com garantia de qualidade com reflexão crítica, na Escócia foram destacadas as carências docentes em área específicas e em regiões rurais, no Brasil considero que essa necessidade é ainda mais ampla pela natureza continental do país e suas diferentes especificidades, mas sabemos que já houveram cursos aligeirados que formaram professores sem a devida qualidade e crítica (ver (RABELO, 2016), portanto é preciso tomar cuidado para não cairmos no risco que citamos anteriormente no item 3.

6- A formação de professores em nível de mestrado também é algo que tem estado em voga nas discussões internacionais, na Europa os países que adotam o Modelo de Bolonha oferecem o mestrado junto com a graduação (RABELO \& MONTEIRO, 2019), assim o professor sai da universidade com o nível de mestrado, mas como percebemos no livro em pauta, se esse nível traz uma melhor qualidade à formação ou representa a formação de um professor crítico é algo que ainda deve ser muito debatido. Pessoalmente considero que 
geralmente há ganhos, mas novamente precisamos pensar nas especificidades brasileiras, para garantir uma qualidade crítica na formação docente e não uma submissão a modelos internacionais impostos, em uma competição neoliberal, concordando com as considerações presentes no livro.

7- A questão da indução profissional docente - que representa uma atual tendência mundial para implementar esforços para que o professor iniciante receba apoio no início da sua carreira, tentando minimizar o choque de realidade que ele sofre, bem como minimizar o malestar e abandono docente (RABELO, MONTEIRO, 2019) - é descrita pela organizadora do livro, Rachel Shanks ${ }^{2}$, e nos interpela a pensar em como implementar um programa deste tipo no nosso país, pois mesmo que saibamos as dificuldades de se implementar algo nacional por causa das especificidades locais e regionais do Brasil, é interessante refletir sobre os aspectos positivos e negativos destes programas internacionais (ver RABELO, 2019) e em especial os descritos pela autora, como a necessidade dos mentores não serem também avaliadores do estágio probatório dos docentes, da vulnerabilidade dos professores iniciantes, das parcerias e do papel da universidade na indução de professores.

8- Por fim, o último capítulo do livro nos instiga a realizar conjecturas futuras sobre a formação docente no nosso país, como Doherty fez com a situação na Escócia, será que teremos uma continuidade na nossa formação docente, sendo de nível superior, mas desvalorizada e buscada cada vez pelas pessoas mais carentes, sendo uma das profissões menos desejadas? Será que teremos um futuro ainda pior, onde a formação universitária entre em declínio em prol de rotas alternativas sofrendo influências globais internacionais em um viés cada vez mais mercadológico, individualista e onde cada vez mais o professor é desvalorizado sendo considerado apenas um técnico da educação que obedece a ordens? Ou será que podemos imaginar um futuro mais otimista, com a profissão docente sendo mais valorizada, almejada, com formação de nível superior, ou maior, onde o professor seja formado com um maior senso crítico, com parcerias, com indução profissional docente e com maior autonomia nas suas ações?

Finalmente, quero dizer que este é um livro que ressalta a importância da formação de professores e da sua qualidade, que nos deixa várias indagações e inspirações, com isso ambiciono deixar o convite de leitura deste livro para quem quiser mais debates sobre os aspectos apontados, conhecendo o que afirma Carvalho (2013, p. 429) que o sentido da comparação "não deve se limitar ao reconhecimento das semelhanças e diferenças existentes entre os fenômenos, mas explicar por que estes ocorrem ou porque o comportamento da parte

\footnotetext{
${ }^{2}$ Que já publicou anteriormente um artigo no Brasil em dossiê por nós organizado (SHANKS, 2019).
} 
é diverso do todo". Portanto, a possibilidade de fazer comparações internacionais oferece a possibilidade de identificar o idêntico e o específico, o global e o local, o comum e o específico, mostrando alternativas que ultrapassem a mera uniformização ou padronização.

\section{REFERÊNCIAS}

CARVALHO, Elma J. G. Reflexões sobre a importância dos estudos de educação comparada na atualidade. Revista HISTEDBR On-line, Campinas, v. 52, p. 416-435, set, 2013.

RABELO, Amanda Oliveira. Formação dos professores em nível superior no Brasil: da promulgação da lei de diretrizes e bases da educação nacional (LDBEN/1996) até os dias atuais. Educere (Mérida), v. 20, p. 505-514, 2016.

RABELO, Amanda Oliveira. Análise comparada da indução profissional como apoio ao docente iniciante. Currículo Sem Fronteiras, v. 19, p. 81-96, 2019.

RABELO, Amanda Oliveira; MONTEIRO, A. M. Apresentação da sessão temática: Indução profissional: desafios e experiências entre formação e profissão docente. Currículo Sem Fronteiras, v. 19, p. 5-22, 2019.

SHANKS, Rachel, ed. Alfabetização micropolítica e formação profissional de professores iniciantes. Traduzido por RABELO, Amanda Oliveira; MONTEIRO, A. M. Currículo sem Fronteiras, v. 19, n. 1, p. 134-150, jan./abr. 2019.

SHANKS, Rachel (ed). Teacher Preparation in Scotland, Emerald Publishing: UK, 2020.

ZEICHNER, Ken. Políticas de formação de professores nos Estados Unidos: como e porque elas afetam vários países no mundo. Tradutora Cristina Antunes. Belo Horizonte: Autêntica editora, 2013.

ZEICHNER, Ken. The struggle for the soul of teaching and teacher education in the USA, Journal of Education for Teaching, v. 40, n. 5, pp. 551-568, 2014. Disponível em: DOI: 10.1080/02607476.2014.956544. Acesso em: 18 dez. 2020.

\section{SOBRE A AUTORA:}

\section{Amanda Oliveira Rabelo}

Doutora em Ciências da Educação pela Universidade de Aveiro, Pós-doutora em Ciências da Educação pela Universidade de Coimbra e em Educação pela UFRJ; Professora Associada da Universidade Federal Fluminense (UFF); Professora Permanente do Programa de PósGraduação em Ensino da UFF/INFES. Correio eletrônico: amandaorabelo@ hotmail.com (iD http://orcid.org/0000-0001-6488-3138 